\title{
A Double-Hurdle Model of Irish Household Expenditure on Prepared Meals
}

\author{
Carol Newman, Maeve Henchion and Alan Matthews
}

\begin{abstract}
In this paper, Irish households' expenditure on prepared meals for home consumption is analysed using the 1987 and 1994 Irish Household Budget Survey datasets. The aim of the paper is to analyse the factors influencing Irish households' decisions to purchase prepared meals and how much to spend on these food items. This is done using the double-hurdle methodology adjusted for the problems of heteroscedasticity and non-normality. Income elasticities are estimated for household expenditure on prepared meals in both years and significant socio-economic influences are identified. These socio-economic factors are assumed to underpin the tastes and preferences of Irish households, with convenience identified as a significant preference of many household groups.
\end{abstract}

\section{JEL Classification: D12}

Keywords: household expenditure, prepared meals, double-hurdle model, convenience

\footnotetext{
- The first author was funded for this research by a Walsh Fellowship from The National Food Centre, Teagasc and this support is gratefully acknowledged.

${ }^{1}$ Carol Newman: Dept. of Economics, Trinity College Dublin and The National Food Centre, Teagasc Maeve Henchion: The National Food Centre, Teagasc Alan Matthews: Dept. of Economics, Trinity College Dublin Address for correspondence: newmanc@tcd.ie
} 


\section{Introduction}

The prepared consumer foods sector is very diverse including all items which have undergone secondary processing such as ready meals, processed meats, soups, yoghurts, pet food etc. In Ireland, the sector is small compared to the total food sector with sales of $€ 1.78$ billion in 1997, but it is one of the fastest growing sectors of the Irish food industry with future growth rates predicted at $8 \%$ per annum (McCarthy and Pitts, 1999). In this paper, household expenditure on prepared meals is analysed. Prepared meals (often referred to as ready meals) form a small part of the overall prepared consumer foods sector and are defined as meals which can be cooked or microwaved directly and require no further preparation. Throughout Europe, the ready meals market has shown dynamic growth since the 1980s (Meat and Livestock Commission, 1997). A number of factors have been identified in the literature as contributing to this growth.

The first contributing factor is a breakdown of formal family meal eating occasions due to the fact that household members are adopting more individualistic lifestyles, particularly children, with all household members increasingly cooking their own meals (Senauer et al., 1998). Secondly, increasing disposable income has led to an increased level of expenditure on more convenient time-saving and labour-saving foods as consumers are unwilling to spend much time preparing food due to the increasing value placed on leisure time (Food Product Development Centre, 1997; Meat and Livestock Commission, 1997). Thirdly, a redefinition of gender roles leading to an increase in the number of women working outside the home is thought to have led to a general loss in traditional cooking skills and less time available to prepare food in the home (The Food Product Development Centre, 1997; Meat and Livestock Commission, 1997). Declining household size and the increase in the number of 1-2 person households has also led to an increase in the demand for easy-to-serve, 
portion controlled convenience foods (Meat and Livestock Commission, 1997). In a supplyside context, increasing ownership of microwaves and freezers has meant that manufacturers are more willing to develop new ready to eat products (Meat and Livestock Commission, 1997). Finally, McCarthy and Pitts (1999) identify a rise in younger consumers with disposable incomes who are more likely to experiment with new products, have nontraditional eating habits and eat out more often contributing to the increase in demand for prepared consumer foods

McCarthy and Pitts (1999) summarise that all of these factors have resulted in a 'cashrich, time-poor' consumer who drives the demand for prepared consumer foods. The impact of socio-economic characteristics of Irish households on their prepared meals expenditure patterns in 1987 and 1994 is analysed in this paper. Characteristics such as marital status, the presence of children in a household, social status etc. are considered in order to accurately determine the factors influencing Irish consumers' decisions to purchase prepared meals.

Section 2 of this paper provides an overview of the methodology used to estimate Irish households' prepared meals expenditure equations. In Section 3, the data are introduced and discussed. Section 4 deals with the specification and estimation of the model and the results are presented and discussed in Section 5. Section 6 provides a summary of results, conclusions and implications of the research.

\section{Methodology}

In this paper, a double-hurdle model is used to analyse household expenditure patterns on prepared meals. However, given the existence of zero observations on the dependent variable, Tobit and infrequency of purchase models must also be considered. The standard Tobit model originally formulated by James Tobin (1958) was the first model to attempt to handle a censored dependent variable. It attributed the censoring to a standard corner 
solution. Applying this model imposes the assumption that zero expenditure is attributable to economic factors alone. More recently, the Tobit model has been generalised to overcome this restrictive assumption. Firstly, the possibility that zeros are due to non-participation in the market for non-economic reasons is accounted for in the double-hurdle model. Secondly, the infrequency of purchase model allows for zeros due to infrequently purchased goods which arise when a survey period is shorter than the goods purchasing cycle.

In this analysis, all three specifications are applied to Irish households' expenditure on prepared meals. Likelihood ratio and non-nested testing procedures are used to distinguish between the three models (see Table 1). The double-hurdle model is found to be most appropriate methodology in modelling Irish households' expenditure on prepared meals in both 1987 and 1994 and as such is the only model outlined in this paper.

The double-hurdle model, originally formulated by Cragg (1971), assumes that households make two decisions with regard to purchasing an item, each of which is determined by a different set of explanatory variables. In order to observe a positive level of expenditure, two separate hurdles must be passed. A different latent variable is used to model each decision process, with a probit model to determine participation and a Tobit model to determine the expenditure level (Blundell and Meghir, 1987).

$$
\begin{array}{ll}
y_{i 1}^{*}=w_{i}{ }^{\prime} \alpha+v_{i} & \text { Participation decision } \\
y_{i 2}^{*}=x_{i}{ }^{\prime} \beta+u_{i} & \text { Expenditure decision } \\
y_{i}=x_{i}{ }^{\prime} \beta+u_{i} & \text { if } y_{i 1}^{*}>0 \text { and } y_{i 2}^{*}>0 \\
y_{i}=0 & \text { otherwise }
\end{array}
$$

\footnotetext{
${ }^{1}$ Recent applications of the double-hurdle model include Burton, Dorsett and Young's (1996) application of a double-hurdle model to UK household meat expenditure, Jensen and Yen's (1996) application to US food expenditure away from home and Yen and Jones' (1997) application to US household consumption of cheese.
} 
where $y_{i 1}^{*}$ is a latent variable describing the household's decision to participate in the prepared meals market, $y_{i 2}^{*}$ is a latent variable describing household consumption of prepared meals, $y_{i}$ is the observed dependent variable (household expenditure on prepared meals), $w_{i}$ is a vector of variables explaining the participation decision, $x_{i}$ is a vector of variables explaining the expenditure decision, $v_{i}$ and $u_{i}$ are the respective error terms assumed to be independent ${ }^{2}$ and distributed as $v_{i} \sim N(0,1)$ and $u_{i} \sim N\left(0, \sigma^{2}\right)$.

The model is estimated using maximum likelihood estimation procedures. However, to overcome the inconsistency of such estimates in the presence of heteroscedasticity and non-normality of the error terms, necessary specification adjustments are made. To allow for heteroscedasticity, the variance of the errors is allowed to vary across observations by specifying it as a function of a set of continuous variables. In this analysis the standard deviation is specified as:

$$
\sigma_{i}=\exp \left(z_{i}^{\prime} h\right)
$$

where $z_{i}$ are some elements of $x_{i}$ (Jensen and Yen, 1996; Su and Yen, 1996; Yen and Jones, 1997). ${ }^{\text {B }}$ An inverse hyperbolic sine (IHS) transformation of the dependent variable will produce consistent parameter estimates for both models in the presence of non-normality (Burbidge et al., 1988). Reynolds and Shonkwiler (1991) were the first to apply this transformation to the Tobit model. For the double-hurdle model the transformation is:

$$
T\left(\theta y_{i}\right)=\log \left[\theta y_{i}+\left(\theta^{2} y_{i}^{2}+1\right)^{1 / 2}\right] / \theta=\sinh ^{-1}\left(\theta y_{i}\right) / \theta
$$

\footnotetext{
${ }^{2}$ Independence of the error terms is a common assumption in these kinds of models (Jensen and Yen, 1996, Su and Yen, 1996). Dependence of the error terms is not considered in this analysis.

${ }^{3}$ In most empirical applications, the specification of the variance equation, in terms of functional form and variables included, tends to be arbitrary. This exponential specification is chosen as it ensures that the standard deviation $\sigma_{i}$ is strictly positive ( $\mathrm{Su}$ and Yen, 1996).
} 
where $\theta$ is an unknown parameter. ${ }^{\text {G }}$ The likelihood equation for the independent doublehurdle model allowing for heteroscedasticity and a non-normal error structure can be written as follows:

$$
\begin{aligned}
& L(\alpha, \beta, h, \theta)=\prod_{0}\left[1-\Phi\left(w_{i}{ }^{\prime} \alpha\right) \Phi\left(\frac{x_{i}{ }^{\prime} \beta}{\sigma_{i}}\right)\right] \times \\
& \prod_{1}\left[\left(1+\theta^{2} y_{i}{ }^{2}\right)^{-1 / 2} \Phi\left(w_{i}{ }^{\prime} \alpha\right) \sigma_{i}^{-1} \phi\left(\frac{T\left(\theta y_{i}\right)-x_{i}{ }^{\prime} \beta}{\sigma_{i}}\right)\right]
\end{aligned}
$$

The estimated coefficients in the double-hurdle model cannot be interpreted in the same way as in a linear regression model. To assess the impact of the regressors on the dependent variable, it is necessary to analyse their marginal effects. This involves decomposing the unconditional mean into the effect on the probability of purchase and the effect on the conditional level of expenditure $\mathrm{B}^{\mathrm{B}}$ and differentiating these components with respect to each explanatory variable. ${ }^{6}$ The unconditional mean can be written as:

$$
E\left[y \mid x_{i}\right]=P\left(y_{i}>0\right) E\left(y_{i} \mid y_{i}>0\right)
$$

The probability of participation and the level of expenditure conditional on participation are (Jensen and Yen, 1996; Yen and Jones, 1997):

$$
\begin{aligned}
& P\left(y_{i}>0\right)=\Phi\left(w_{i}{ }^{\prime} \alpha\right) \Phi\left(\frac{x_{i}{ }^{\prime} \beta}{\sigma_{i}}\right) \\
& E\left(y_{i} \mid y_{i}>0\right)=\Phi\left(\frac{x_{i}{ }^{\prime} \beta}{\sigma_{i}}\right)^{-1} \int_{0}^{\infty}\left(\frac{y_{i}}{\sigma_{i} \sqrt{1+\theta^{2} y_{i}^{2}}} \phi\left(\frac{T\left(\theta y_{i}\right)-x_{i}{ }^{\prime} \beta}{\sigma_{i}}\right)\right) d y_{i}
\end{aligned}
$$

For the continuous explanatory variables, these marginal effects are used to calculate elasticities at the sample means. For the discrete or categorical variables, the marginal effects

\footnotetext{
${ }^{4}$ For examples of the application of the IHS transformation to the double-hurdle model see Jensen and Yen (1996) and Yen and Jones (1997).

${ }^{5}$ This decomposition follows the reasoning applied by McDonald and Moffitt (1980) in their decomposition of the unconditional mean of the dependent variable in the Tobit model.

${ }^{6}$ For details of the derivations contact the first author.
} 
are used to calculate percentage changes in the dependent variable when the variable shifts from zero to one, ceteris paribus.

\section{Data}

The data used in this analysis are extracted from the 1987/8 and 1994/5 Irish Household Budget Surveys collected by the Central Statistics Office of Ireland. ${ }^{\text {B }}$ The 1987/8 and 1994/5 surveys covered random samples of 7,705 and 7,877, urban and rural households, respectively throughout the country. Data were collected on households' socio-economic characteristics and an extensive weekly expenditure diary was reported for each household. The reference person for qualitative variables is the head of household as reported in the survey. Characteristics of the household meal planner would provide a more accurate indication of socio-economic effects, but this information is not collected in the survey.

Only households whose size is identifiable from the Household Budget Survey are included in this analysis. They range from single-adult households to households with four adults, with and without children. Therefore, the sample size in 1987 is 7,112 households and in 1994 is 7,332 households. The variables used in this analysis are listed and described in Table 2. All expenditure variables are adjusted for seasonality by regressing each expenditure variable on monthly dummies and constructing an index using the estimated coefficients. Expenditure variables are also adjusted for household size using EU adult equivalence scales as reported in the Household Budget Survey data set. Sample statistics are presented in Table 3.

The dependent variable in this analysis is household expenditure on prepared meals. Information on the value of household expenditure only is collected and so quantity and

\footnotetext{
${ }^{7}$ Standard errors of the estimated marginal effects are computed using the 'delta method' (Su and Yen, 1996). Details may be obtained from the first author.

${ }^{8}$ The Irish Household Budget Survey is conducted every 7 years. The 2000 Irish Household Budget Survey will become available at the end of 2001.
} 
quality effects cannot be separately identified. The dependent variable is assumed to be expressible as a linear combination of the matrix of explanatory variables consisting of income and the various socio-economic characteristics, assumed to underpin tastes and preferences.

\section{Model Specification and Estimation}

Theory provides no guidance as to which explanatory variables to include in the first and second hurdles of the double-hurdle model. Including the same set of regressors in each hurdle makes it difficult to identify the parameters of the model correctly and so exclusion restrictions must be imposed (Jones, 1992; Yen et al., 1996). An underlying assumption of the double-hurdle model is that the first hurdle is a function of non-economic factors determining households' decisions to participate in the market. Therefore, economic factors, namely income and income squared, are excluded from the first equation. The variance equation is specified as a function of the continuous variables of the model (Yen and $\mathrm{Su}$, 1995; Jensen and Yen, 1996; Su and Yen, 1996).

The double-hurdle model with specification adjustments for heteroscedasticity and nonnormality is estimated for household expenditure on prepared meals for each year by maximising the log of the relevant likelihood function, using the Maxlik procedure in Gauss version 3.5. Likelihood ratio tests reject the restricted model of homoscedasticity in favour of the alternative variance specification (see Table 4). Variables statistically insignificant in the variance equation are excluded with the final variance specification including both income and age. Likelihood ratio tests also unanimously reject the normality restriction in favour of the IHS specification (see Table 4). The significance of the IHS parameter, $\theta$, also justifies the use of this specification (see Table 5). 


\section{Empirical Results}

Maximum likelihood estimates for the double-hurdle model of household expenditure on prepared meals are presented in Table 5. Marginal effects of the explanatory variables and their associated standard errors are evaluated ${ }^{9}$ and used to calculate elasticities for the continuous variables of the model, calculated at the sample means, and discrete effects for the categorical variables. These are presented in Table 6. The significance levels of these elasticities and discrete effects are based on the significance levels of their underlying marginal effects.

\section{Income}

In both 1987 and 1994, income has a positive and significant effect on household expenditure on prepared meals. Income squared is included in the analysis to capture the possibility of a non-linear relationship between income and expenditure on prepared meals. In both years, the effect of this variable is negative and significant. This implies that as household income increases, expenditure on prepared meals also increases but at a decreasing rate.

Income elasticity estimates for the IHS heteroscedastic double-hurdle model are positive and significant for prepared meals in each year, at 0.380 in 1987 and 0.352 in 1994 . The effects on the probability of participation and the conditional level of expenditure are also positive and significant. The magnitude of the income elasticity has declined between 1987 and 1994, however, evaluating the unconditional income elasticity in 1994 at the 1987 sample mean, adjusted for changes in the money value of income over time, reveals that between the two years the income elasticity has declined by only 0.03 percent (see Table 6). The nonlinear relationship between income and expenditure implies that the responsiveness of

\footnotetext{
${ }^{9}$ For marginal effects and associated standard errors contact first author.
} 
households' expenditure on prepared meals to changes in income declines as income increases, but income remains as important an explanatory factor in 1994 as in 1987 in terms of the magnitude of its effect.

\section{Age}

The effect of the age of the head of household on household expenditure on prepared meals is negative and significant in both years. This negative result is evident in the effect on the probability of purchase, the conditional level of expenditure and the unconditional level of expenditure. This result implies that the younger the head of household, the more likely they are to purchase prepared meals. Of households that do participate in this market, the younger the head of household the more, on average, that is spent on these food items.

This result is consistent with the literature outlined in Section 1 which suggested that younger headed households both have a preference for a convenient lifestyle and have nontraditional eating habits, and so relative to older households purchase more prepared meals. However, between 1987 and 1994 the unconditional age elasticity has declined by just under a third. This implies that expenditure on prepared meals is less sensitive to the age of the head of household in 1994 compared with 1987, evidence that the preferences of older and younger households with regard to expenditure on prepared meals are converging.

\section{All-Working}

The first discrete variable captures the difference between households where all adult members work and households where at least one adult member is without a job. The discrete effect is negative and significant in 1987 but insignificant in 1994 . While the effect on the probability of participation is negative and significant in both years, the effect on the conditional level of expenditure is negative and significant in 1987 only. 
This result is surprising as one would expect all-working households to have a greater desire for timesaving, and therefore to spend more on convenience foods, since no adult member remains in the home engaged in home duties. Examination of the 1994 Household Budget Survey shows that the average weekly expenditure of all-working households on food consumed away from home is IR£10.29 (€13.07), compared with other households who spend on average IR£4.49 (€5.70) weekly. This suggests that all-working household members could be substituting the more convenient alternative of eating out of home for home-cooking alternatives, even based on prepared meals.

\section{Urban}

The urban variable has a positive effect on prepared meals expenditure. The discrete effects show that, ceteris paribus, households living in urban areas spend 17 percent more on prepared meals than households living in rural areas in both 1987 and 1994. In both years urban households are 10 percent more likely to participate in this market than rural households, ceteris paribus. Of all households that purchase these foods, ceteris paribus, urban households spend 7-8 percent more.

This significant difference between urban and rural households could be identifying a difference in the choices urban and rural dwellers make with regard to home cooking due to differences in the types of lifestyles they lead. For example, urban dwellers may face greater time constraints in commuting to and from work due to traffic congestion, and so have less time to prepare meals in the home. As a result, urban households may be more 'time-poor' than their rural counterparts and so spend more on prepared meals. Another explanation may be that urban households have greater availability and choice of prepared meals on offer to them compared with rural households and so are more likely to purchase these products and spend more on them. 


\section{Children}

The presence of children in a household has a positive and significant effect on expenditure on prepared meals in both years. In 1987, the unconditional effect is 0.74 implying that, ceteris paribus, overall households with children spend on average 74 percent more on prepared meals than households without. In 1994, this effect has declined but remains substantial at 33 percent. In 1994, the effect on the probability of participation is positive and significant while the effect on the conditional level of expenditure is negative and significant. This implies that, ceteris paribus, households with children in 1994 are 40 percent more likely to participate in the prepared meals market, but of all participating households, households with children spend 8 percent less than households without. This result might be explained by suggesting that, while children demand more prepared meals, on an adult equivalent basis, they consume less per head due to the fact that they require smaller portions.

The literature suggests that increasingly consumers are adopting an individualistic lifestyle (Food Product Development Centre, 1997; Meat and Livestock Commission, 1997; Senauer et al., 1998). This implies that the role of the family meal-eating occasion is declining as individual household members increasingly satisfy their own preferences and prepare and consume their own meals. Senauer et al. (1998) reveal that two-thirds of children in the U.S. prepared at least one meal a week without supervision in 1990. The effect of households with children on prepared meals found in this analysis could also be reflecting this pattern as households with children are more likely to purchase prepared meals, which children themselves could easily prepare. 


\section{Gender}

The gender of the head of household has a positive effect on household expenditure on prepared meals in both 1987 and 1994. In 1987, the unconditional effect of a female head of household compared to a male is 11 percent while in 1994 it has risen to 16 percent. The effect on the conditional level of expenditure in both years is insignificant, implying that the overall positive result is driven by the greater likelihood of participation of female-headed households in this food market than male-headed households in both years. The most likely explanation for the positive effect of gender is that female-headed households have a greater desire for convenience than male-headed households. Analysing expenditure of these household groups on food consumed away from home reveals however, that male-headed households spend on average IR£5.47 (€6.95) while female-headed households spend IR£4.66 (€5.92) on average, suggesting that female-headed households' greater desire for convenience than male-headed households only extends to food purchased for home preparation.

The female-headed household group is explored further by examining the characteristics of those who participate in the prepared meals market and those who do not. This leads to the identification of two distinct female-headed household groups. Eight three percent of participating female-headed households live in urban areas, 54 percent have children, 43 percent are single and 17 percent are married. Their average age is 46 compared with the average age of non-participating female-headed households of 61 . It can therefore be concluded that participating female-headed households are young, are more likely to live in urban areas and a large percentage of them have children. On the other hand, older femaleheaded households, 72 percent of whom live alone, are not participating in the market. 


\section{Education}

In 1987, the education level of the head of household is insignificant in explaining the overall household expenditure on prepared meals, but in 1994 educated heads of household spend 12 percent more on prepared meals than the base category, ceteris paribus. The difference in the effect of this variable over time is also evident in its effect on the probability of participation and the conditional level of purchase in each year. In 1987, education has an insignificant effect on the decision to participate in the prepared meals expenditure market. However, conditional on purchase, educated households spend 4 percent less than the base category, ceteris paribus. In 1994, however, educated households are 11 percent more likely to purchase prepared meals, ceteris paribus, but conditional on purchase do not spend a significantly different amount than the base category.

It has been suggested in the literature that educated households are more health conscious than other households. ${ }^{10}$ The negative result observed in 1987 might therefore be explained by the fact that educated households perceived prepared meals to be unhealthy. However, the positive result observed in 1994 could illustrate a change in consumers' perception of this food category in relation to its perceived healthiness. This change could be attributed to the greater availability of healthy options in the prepared meals category in 1994 compared with 1987 resulting in educated households being more likely to purchase these products than other households.

\section{Social Status}

Similar to the effect of education on prepared meals expenditure, the social status of the head of household is insignificant in explaining household expenditure on prepared consumer foods in 1987 but has a significant and positive effect on expenditure in 1994. In

\footnotetext{
${ }^{10} \mathrm{Su}$ and Yen (1996) also found a negative relationship between education and US pork consumption and attributed this to the negative perception of meat of more educated households.
} 
1994, ceteris paribus, heads of household of a professional social status spend 10 percent more overall on prepared meals than the base category, manual and agricultural workers, and farmers, while heads of household of an intermediate social status spend 6 percent more than the base.

The positive effect of social status on prepared meals expenditure might be attributed to the fact that professional households and households of an intermediate social status face greater time constraints than other households and so have a greater preference for time saving in meal preparation. As a result, they are more likely to purchase prepared meals than other household groups. This possible time saving preference can also be seen in the expenditure of these groups on food consumed away from home. The 1994 data set shows that professional households spend on average IR£22.48 (€28.54) weekly on food consumed away from home compared with the intermediate social group who spend on average IR£13.28 (€15.59) and the base category who spend on average IR£7.45 (€9.46).

\section{Marital Status}

\section{Single adult}

In both 1987 and 1994, the overall effect of single adult households is insignificant. However, examination of the breakdown of this effect into the effect on the probability of participation and the level of expenditure conditional on participation reveals some interesting findings. While single adult households are less likely to purchase prepared meals, those that do spend on average 14 percent and 12 percent more than the base category in 1987 and 1994 respectively, ceteris paribus.

The results observed on the probability of participation and the conditional level of expenditure suggests that there are two opposing forces at work. Separating single adult households into participating and non-participating groups reveals that the average age of 
participating single adult households is 47 while the average age of non-participating single adult households is 62 . While age is controlled for in the analysis, this observation provides some insight into the factors driving the expenditure decisions of single-adult households. The negative effect on the probability of participation could be attributed to the fact that many single-adult households are pensioners, living alone and with more time to prepare home cooked meals. Therefore, they do not require or demand the added value of convenience the purchase of prepared meals offers. On the other hand, of all participating households, single adult households spend more on prepared meals than other households, suggesting that they have a greater desire for convenience in the preparation of meals in the home. This could be explained by the fact that, firstly, there is less incentive to prepare a home cooked meal when cooking for one and, secondly, prepared meals are often conveniently packaged for one compared with other home cooking alternatives.

\section{Married couples}

The discrete effect of this variable reveals that, ceteris paribus, married couples spend more on prepared consumer foods than other households, with two or more unmarried adults, in both 1987 and 1994. However, the magnitude of this effect has declined from 0.213 to 0.093 between the two years. In 1987, a positive effect is observed on both the probability of participation and the conditional level of expenditure. In 1994, however, the positive result is motivated by the fact that households containing a married couple are more likely to participate in the prepared meals market, but conditional on participation, spend on average less. These results suggest that certain married households have a greater desire for convenience and therefore a greater likelihood of participation in the prepared meals market than other household groups. However, compared with other participating households married households spend less on prepared meals. This may be because, while convenience is 
of some importance to this household group relative to other households, they still have a greater preference for home-cooked meals than other participating households.

\section{Household Appliances}

In Section 1, the growth in demand for prepared consumer foods was partly attributed to increased microwave and freezer ownership (Meat and Livestock Commission, 1997). For this reason household ownership of these appliances is included in this analysis. While these appliances are often not necessary for the consumption of prepared meals they can add to the convenience attribute of these products in terms of cooking and storage. Ownership of a microwave in particular is important as many prepared meal products can only be cooked using a microwave. As a result, households without a microwave are automatically excluded from the consumption of certain prepared meal products. 1 In 1987,6 percent of surveyed households owned a microwave while 15 percent owned a freezer. By 1994, these figures had risen to 46 percent and 22 percent respectively.

\section{Microwave}

In 1987, household ownership of a microwave is insignificant in explaining overall expenditure on prepared meals. However, of all participating households, those that own a microwave spend 4 percent more than those that do not. In 1994, households in possession of a microwave spend 24 percent more overall on prepared meals than households without. They are 20 percent more likely to participate in the market and conditional on participation, spend 4 percent more. The fact that the overall effect of microwave ownership is insignificant in 1987 but positive and significant in 1994 might be because of the small sample of microwave owners in the 1987 dataset.

\footnotetext{
11 The Household Budget Survey does not break the prepared meals category into microwavable and nonmicrowavable and so this sample selection problem cannot be incorporated into the analysis.
} 


\section{Ownership of a freezer}

In 1987, households in possession of a freezer spend 11 percent less overall on prepared meals than households without. This overall result is attributable to the negative effect of this variable on the probability of purchase, that is, households with a freezer are less likely to participate in the prepared meals market. This result might arise if households with a freezer are less likely to participate in the market in the week surveyed due to the fact that they can store the goods for a longer period of time than households without a freezer. This suggests that this variable is reflecting an infrequency of purchase problem rather than nonparticipation as captured by the double-hurdle model. Yen and Huang (1996) identify that often survey data does not contain detailed enough information to correctly identify different sources of zero observations and the probability of consumption can also reflect the probability of purchase. This implies that infrequency of purchase can also be important within a double-hurdle framework. Using this reasoning, the result for the ownership of a freezer variable can therefore be interpreted in an infrequency of purchase context. In 1994, ownership of a freezer is insignificant in explaining expenditure on prepared meals.

\section{Summary and Conclusions}

The prepared meals market has shown dynamic growth across Europe since the 1980s, which has largely been attributed to changing social structures (Meat and Livestock Commission, 1997). In this paper, the economic and socio-economic factors influencing Irish households' expenditure on prepared meals in 1987 and 1994 are analysed in an attempt to explain the factors contributing to the growth of this sector. The analysis applied Tobit, double-hurdle and infrequency of purchase methodologies, adjusted for the problems of heteroscedasticiy and non-normality, to the $1987 / 8$ and 1994/5 Irish Household Budget 
Survey datasets. The double-hurdle model was found to be the most appropriate modelling technique based on relevant specification testing procedures.

The observed decline in the estimated income elasticities accompanied by the significant non-linear relationship between income and expenditure on prepared meals provides evidence that the effect of income on prepared meals expenditure follows the same pattern as other food items. That is, as income increases, the influence it has on food expenditure decisions declines in importance. Understanding the factors shaping expenditure decisions becomes increasingly important with increasing income levels.

In this paper, differences in the pattern of expenditure on prepared meals of different household groups are explained through differences in their preferences for convenience. Younger households, urban households, households with children, female-headed households and educated households of a professional social status, all have a greater preference for convenience than other households as illustrated in their expenditure patterns on prepared meals. All-working households purchase and spend less than other households on prepared meals, however average weekly household expenditure of this household group on food consumed out of home is substantially higher than other households. Thus all-working households may be substituting eating out of home for all types of home cooking. Mixed results are observed for the marital status variable. While the presence of a large number of older single adult households leads to a negative effect on the probability of this household group participating in the prepared meals market, younger urban dwelling single adult households exhibit a greater preference for convenience than other participating households by spending more on prepared meals. Similarly, while married couples are more likely to participate in the prepared meals market, compared to households with two or more unmarried adults, they spend less, suggesting that while they have some level of preference 
for convenience compared to other households, it is not as strong as for other household groups.

The main implication of the results reported in this paper is that economic incentives alone may not be as effective in maintaining or stimulating demand for prepared meals as strategies marketing the attributes of food that changing lifestyles demand. Focusing on quality and nutritional aspects could also encourage consumption. In the late 1990s and early 2000s, lifestyles across Europe and more specifically in Ireland have been converging. An increase in the proportion of the Irish population of working age, an increase in third level graduates, an explosion of population in urban areas, and government incentives aimed at expanding labour supply increasing the number of all-working households in Ireland, will all shape the food market of the future. It is therefore increasingly important for the food industry to identify the attributes of food products desired by these consumers who form an increasing proportion of the Irish and European population. With the publication of the 2000 Irish Household Budget Survey dataset, the results of this analysis can be validated and the degree to which the changing demographics and socio-economics of the population in the late 1990s has impacted on household expenditure on prepared meals can be further explored. 


\section{References}

Blundell, R. and Meghir, C. (1987) Bivariate Alternatives to the Univariate Tobit Model, Journal of Econometrics, 34, 179-200.

Burbidge, J., Magee, L. and Robb, A. (1988) Alternative Transformations to Handle Extreme Values of the Dependent Variable, Journal of the American Statistical Association, 83, 123127.

Burton, M., Dorsett, R. and Young, T. (1996) Changing Preferences for Meat: Evidence from UK household data, 1973-1993, European Review of Agricultural Economics, 23, 357-370.

Cragg, J. (1971) Some Statistical Models for Limited Dependent Variables with Application to the Demand for Durable Goods, Econometrica, 39, 829-844.

Central Statistics Office (1988). Statistical Release. Dublin: Government Information Services.

Central Statistics Office (1995). Statistical Release. Dublin: Government Information Services.

Food Product Development Centre. (1997) Prepared Consumer Foods: The Way Forward, Dublin Institute of Technology Working Paper.

Jensen, H. and Yen, S. (1996) Food Expenditures Away From Home by Type of Meal, Canadian Journal of Agricultural Economics, 44, 67-80.

Jones, A. (1992) A Note on Computation of the Double-Hurdle Model with Dependence with an Application to Tobacco Expenditure, Bulletin of Economic Research, 44, 67-74.

McCarthy, B. and Pitts, E. (1999) The Irish Prepared Consumer Food Sector: Factors Contributing to Sustainable Competitive Advantage, National Food Centre Working Paper. 
McDonald, J. and Moffitt, R. (1980) The Uses of Tobit Analysis, The Review of Economics and Statistics, 62, 318-312.

Meat and Livestock Commission. (1997) Ready Meals Market in Europe, Meat Demand Trends, May, 14-25.

Reynolds, A. and Shonkwiler, J. (1991) Testing and Correcting for Distributional Misspecifications in the Tobit Model: An Application of the Information Matrix Test, Empirical Economics, 16, 313-323.

Senauer, B., Asp, E. and Kinsey, J. (1998) Food Trends and the Changing Consumer, Minnesota: Eagan Press.

Su, S. and Yen, S. (1996) Microeconometric Models of Infrequently Purchased Goods: An Application to Household Pork Consumption, Empirical Economics, 21, 513-533.

Tobin, J. (1958) Estimation of Relationships for Limited Dependent Variables, Econometrica, 26, 24-36.

Vuong, Q. (1989) Likelihood Ratio Tests for Model Selection and Nonnested Hypotheses, Econometrica, 57, 307-333.

Yen, S. and Huang, C. (1996) Household Demand for Finfish: A Generalized Double-Hurdle Model, Journal of Agricultural and Resource Economics, 21, 202-234.

Yen, S., Jensen, H. and Wang, A. (1996) Cholesterol Information and Egg Consumption in the US: A Non-normal and Heteroscedastic Double Hurdle Model, European Review of Agricultural Economics, 23(3), 343-356.

Yen, S. and Jones, A. (1997) Household Consumption of Cheese: An Inverse Hyperbolic Sine Double-Hurdle Model with Dependent Errors, American Journal of Agricultural Economics, 79, 246-251. 
Yen, S. and Su, S. (1995) Modelling US Butter Consumption with Zero Observations, Agricultural and Resource Economics Review, April, 47-55. 


\section{Tables}

Table 1. Likelihood Ratio tests of Tobit specification

\begin{tabular}{|c|c|c|c|c|c|c|}
\hline & \multicolumn{2}{|c|}{$\begin{array}{l}\mathrm{H}_{0}=\text { Tobit Specification } \\
\mathrm{H}_{1}=\text { Double Hurdle } \\
\text { Specification }\end{array}$} & \multicolumn{2}{|c|}{$\begin{array}{l}\mathrm{H}_{0}=\text { Tobit Specification } \\
\mathrm{H}_{1}=\text { Infrequency of } \\
\text { Purchase Specification }\end{array}$} & \multicolumn{2}{|c|}{$\begin{array}{l}\mathrm{H}_{0}=\text { No difference between } \\
\text { IFP and DH Models }\end{array}$} \\
\hline & 1987 & 1994 & 1987 & 1994 & 1987 & 1994 \\
\hline Test Statistic & 510.58 & 569.69 & 450.10 & 534.00 & 4.437 & 7.361 \\
\hline \multirow[t]{3}{*}{ Critical Value } & $\chi_{13,0.01}^{2}=$ & $\chi_{13,0.01}^{2}=$ & $\chi_{13,0.01}^{2}=$ & $\chi_{13,0.01}^{2}=$ & $z=2.362$ & $z=2.362$ \\
\hline & 27.69 & 27.69 & 27.69 & 27.69 & & \\
\hline & Reject $\mathrm{H}_{0}$ & Reject $\mathrm{H}_{0}$ & Reject $\mathrm{H}_{0}$ & Reject $\mathrm{H}_{0}$ & $\begin{array}{l}\text { Reject } \mathrm{H}_{0} \text { in } \\
\text { favour of } \mathrm{DH}\end{array}$ & $\begin{array}{l}\text { Reject } \mathrm{H}_{0} \text { in } \\
\text { favour of } \\
\mathrm{DH}\end{array}$ \\
\hline
\end{tabular}

Vuong's test for model Vuong's test for $\mathrm{H}_{0}=$ No difference between

DH: Double Hurdle Model, IFP: Infrequency of Purchase Model

${ }^{\Omega}$ See Vuong, 1989

Table 2. Variable descriptions

\begin{tabular}{|c|c|}
\hline \multicolumn{2}{|l|}{ Dependent } \\
\hline $\begin{array}{l}\text { Prepared Meals } \\
\text { Independent } \\
\end{array}$ & Seasonally adjusted per capita household weekly expenditure on prepared meals (£IRL) \\
\hline Continuous & \\
\hline Income & $\begin{array}{l}\text { Proxied by seasonally adjusted per capita total weekly household expenditure and scaled } \\
\text { by } 100 \text { (£IRL) }\end{array}$ \\
\hline Income $^{2}$ & Income squared (£IRL) \\
\hline Age & Age group of head of household (1-8) \\
\hline \multicolumn{2}{|l|}{ Discrete } \\
\hline All-working & $\begin{array}{l}1=\text { Household in which all adults work } \\
0=\text { At least one adult does not work }\end{array}$ \\
\hline Urban & $\begin{array}{l}1=\text { Urban household } \\
0=\text { Rural household }\end{array}$ \\
\hline Gender & $\begin{array}{l}1=\text { Female head of household } \\
0=\text { Male head of household }\end{array}$ \\
\hline Children & $\begin{array}{l}1=\text { Children present } \\
0=\text { No children present }\end{array}$ \\
\hline Education $^{\mathrm{a}}$ & $\begin{array}{l}1=\text { Head of household left school at age } 17 \text { or over } \\
0=\text { Head of household left school under the age of } 17\end{array}$ \\
\hline Education $^{\mathrm{b}}$ & $\begin{array}{l}1=\text { Head of household has Leaving Certificate or a higher level of education } \\
0=\text { Head of household has less than Leaving Certificate education }\end{array}$ \\
\hline Social1, Social2 & $\begin{array}{l}\text { Social1 }=1 \text { for head of household categorised as higher professional, lower professional, } \\
\text { employer or manager, } 0 \text { otherwise } \\
\text { Social } 2=1 \text { for head of household categorised as salaried employee, intermediate non- } \\
\text { manual, other non-manual, } 0 \text { otherwise } \\
\text { Base category = head of household categorised as manual workers, farmers and other } \\
\text { agricultural workers or fishermen }\end{array}$ \\
\hline Single, Married & $\begin{array}{l}\text { Single }=1 \text { for single adult household with or without children, } 0 \text { otherwise } \\
\text { Married }=1 \text { for married couple with no other adults with or without children, } 0 \text { otherwise } \\
\text { Base category }=\text { households with } 2 \text { or more adults with or without children }\end{array}$ \\
\hline Microwave & $\begin{array}{l}1=\text { Household is in possession of a microwave } \\
0=\text { Otherwise }\end{array}$ \\
\hline Freezer & $\begin{array}{l}1=\text { Household is in possession of a freezer } \\
0=\text { Otherwise }\end{array}$ \\
\hline
\end{tabular}


Table 3. Sample statistics

\begin{tabular}{|c|c|c|c|c|c|c|c|c|}
\hline \multirow[b]{2}{*}{ Variable } & \multicolumn{2}{|c|}{ Mean (IRL£) } & \multicolumn{2}{|c|}{ Std. Dev. (IRL£) } & \multicolumn{2}{|c|}{ Maximum (IRL£) } & \multicolumn{2}{|c|}{$\%$ Zeros } \\
\hline & 1987 & 1994 & 1987 & 1994 & 1987 & 1994 & 1987 & 1994 \\
\hline Prepared Meals & 0.128 & 0.457 & 0.210 & 0.826 & 3.56 & 23.21 & $51 \%$ & $57 \%$ \\
\hline Income & 0.936 & 1.182 & 0.604 & 0.806 & 7.16 & 8.59 & & \\
\hline Income $^{2}$ & 1.241 & 2.047 & 2.045 & 3.498 & 51.34 & 73.77 & & \\
\hline Age & 4.938 & 5.082 & 1.707 & 1.701 & 8 & 8 & & \\
\hline All-working & 0.224 & 0.267 & & & & & & \\
\hline Urban & 0.628 & 0.646 & & & & & & \\
\hline Children & 0.587 & 0.539 & & & & & & \\
\hline Gender & 0.227 & 0.279 & & & & & & \\
\hline Education & 0.332 & 0.335 & & & & & & \\
\hline Sociall & 0.294 & 0.311 & & & & & & \\
\hline Social2 & 0.306 & 0.277 & & & & & & \\
\hline Single & 0.224 & 0.280 & & & & & & \\
\hline Married & 0.539 & 0.471 & & & & & & \\
\hline Microwave & 0.059 & 0.457 & & & & & & \\
\hline Freezer & 0.155 & 0.216 & & & & & & \\
\hline
\end{tabular}

Table 4.

Likelihood ratio tests of homoscedasticity restriction

$\mathrm{H}_{0}=$ Homoscedastic Error Structure $\mathrm{H}_{1}=$ Heteroscedastic Error Specification
Likelihood ratio test of normality restriction

$\mathrm{H}_{0}=$ Untransformed Dependent Variable

$\mathrm{H}_{1}=\mathrm{IHS}$ Transformation to Dependent Variable

\begin{tabular}{lllll} 
& 1987 & 1994 & 1987 & 1994 \\
\hline Test Statistic & 32.56 & 305.19 & 2936.55 & 3626.59 \\
Critical Value & $\chi_{2,0.01}^{2}=9.21$ & $\chi_{2,0.01}^{2}=9.21$ & $\chi_{1,0.01}^{2}=6.63$ & $\chi_{1,0.01}^{2}=6.63$ \\
& Reject $\mathrm{H}_{0}$ & Reject $\mathrm{H}_{0}$ & Reject $\mathrm{H}_{0}$ & ${\text { Reject } \mathrm{H}_{0}}$ \\
\hline
\end{tabular}


Table 5.

Maximum likelihood estimates of IHS heteroscedastic double-hurdle model

\begin{tabular}{|c|c|c|c|c|c|c|}
\hline & \multicolumn{3}{|l|}{1987} & \multicolumn{3}{|l|}{1994} \\
\hline & Part. & Exp. & Hetero. & Part. & Exp. & Hetero. \\
\hline \multirow[t]{2}{*}{ Constant } & $1.085^{* * *}$ & $0.046^{* * *}$ & $-2.499 * * *$ & $0.579 * * *$ & $0.134 * * *$ & $-1.540 * * *$ \\
\hline & $(0.159)$ & $(0.007)$ & $(0.034)$ & $(0.143)$ & $(0.017)$ & $(0.035)$ \\
\hline \multirow[t]{2}{*}{ Income } & & $0.034 * * *$ & $0.090 * * *$ & & $0.094 * * *$ & $0.058 * * *$ \\
\hline & & $(0.006)$ & $(0.023)$ & & $(0.011)$ & $(0.017)$ \\
\hline \multirow[t]{2}{*}{ Income 2} & & $-0.011 * *$ & & & $-0.011 * * *$ & \\
\hline & & $(0.002)$ & & & $(0.002)$ & \\
\hline \multirow[t]{2}{*}{ Age } & $-0.329 * * *$ & $-0.002 * *$ & & $-0.219 * * *$ & $-0.008 * * *$ & \\
\hline & $(0.022)$ & $(0.001)$ & & $(0.020)$ & $(0.002)$ & \\
\hline \multirow[t]{2}{*}{ All Working } & -0.031 & $-0.011 * *$ & & -0.100 & -0.001 & \\
\hline & $(0.091)$ & $(0.003)$ & & $(0.080)$ & $(0.006)$ & \\
\hline \multirow[t]{2}{*}{ Urban } & 0.082 & $0.013 * * *$ & & $0.124 * *$ & $0.030 * * *$ & \\
\hline & $(0.072)$ & $(0.002)$ & & $(0.062)$ & $(0.005)$ & \\
\hline \multirow[t]{2}{*}{ Children } & $1.603 * * *$ & -0.004 & & $1.015 * * *$ & $-0.031 * * *$ & \\
\hline & $(0.094)$ & $(0.003)$ & & $(0.098)$ & $(0.007)$ & \\
\hline \multirow[t]{2}{*}{ Gender } & $0.246 * * *$ & -0.001 & & $0.420 * * *$ & -0.002 & \\
\hline & $(0.091)$ & $(0.004)$ & & $(0.073)$ & $(0.007)$ & \\
\hline \multirow[t]{2}{*}{ Education } & 0.095 & $-0.007 * * *$ & & $0.232 * * *$ & 0.006 & \\
\hline & $(0.083)$ & $(0.002)$ & & $(0.073)$ & $(0.006)$ & \\
\hline \multirow[t]{2}{*}{ Sociall } & 0.086 & -0.002 & & $0.258 * * *$ & -0.003 & \\
\hline & $(0.090)$ & $(0.003)$ & & $(0.080)$ & $(0.007)$ & \\
\hline \multirow[t]{2}{*}{ Social2 } & 0.035 & 0.002 & & $0.132 *$ & 0.000 & \\
\hline & $(0.078)$ & $(0.002)$ & & $(0.074)$ & $(0.006)$ & \\
\hline \multirow[t]{2}{*}{ Single } & $-0.621 * * *$ & $0.023 * * *$ & & $-0.479 * * *$ & $0.047 * * *$ & \\
\hline & $(0.098)$ & $(0.005)$ & & $(0.088)$ & $(0.010)$ & \\
\hline \multirow[t]{2}{*}{ Married } & $0.213 * * *$ & $0.101 * * *$ & & $0.371 * * *$ & $-0.017 * * *$ & \\
\hline & $(0.085)$ & $(0.003)$ & & $(0.082)$ & $(0.006)$ & \\
\hline \multirow[t]{2}{*}{ Microwave } & 0.050 & 0.006 & & $0.418^{* * *}$ & $0.015 * * *$ & \\
\hline & $(0.141)$ & $(0.004)$ & & $(0.060)$ & $(0.005)$ & \\
\hline \multirow[t]{2}{*}{ Freezer } & $-0.182 *$ & -0.001 & & 0.114 & -0.006 & \\
\hline & $(0.098)$ & $(0.003)$ & & $(0.074)$ & $(0.005)$ & \\
\hline \multirow[t]{2}{*}{ IHS } & & $5.039 * * *$ & & & $2.084 * * *$ & \\
\hline & & $(0.247)$ & & & $(0.092)$ & \\
\hline Log Likelihood & -169.22 & & & -2102.26 & & \\
\hline
\end{tabular}

Part.: Participation equation, Exp: Expenditure equation, Hetero.: Heteroscedasticity equation $* * *$ significant at $1 \%$ level, ** significant at $5 \%$ level, * significant at $10 \%$ level

Standard errors are given in parentheses. 
Table 6. $\quad$ Elasticity estimates and discrete effects for IHS heteroscedastic double-hurdle

\begin{tabular}{|c|c|c|c|c|c|c|}
\hline & $\begin{array}{l}1987 \\
\text { Prob. }\end{array}$ & Cond. & Uncond. & $\begin{array}{l}1994 \\
\text { Prob. }\end{array}$ & Cond. & Uncond. \\
\hline \multicolumn{7}{|l|}{ Elasticities } \\
\hline Income $^{\Omega}$ & $0.114 * * *$ & $0.266^{* * *}$ & $0.380^{* * *}$ & $0.099 * * *$ & $0.253 * * *$ & $0.352 * * *$ \\
\hline Age & $-0.851 * * *$ & $-0.055^{* *}$ & $-0.906 * * *$ & $-0.552 * * *$ & $-0.096 * * *$ & $-0.648 * * *$ \\
\hline \multicolumn{7}{|c|}{ Discrete Effects } \\
\hline All Working & $-0.063 *$ & $-0.066 * * *$ & $-0.130 * * *$ & $-0.046^{*}$ & -0.002 & -0.048 \\
\hline Urban & $0.096 * * *$ & $0.078 * * *$ & $0.174 * * *$ & $0.100 * * *$ & $0.073 * * *$ & $0.173 * * *$ \\
\hline Children & $0.767 * * *$ & -0.024 & $0.743 * * *$ & $0.405 * * *$ & $-0.078 * * *$ & $0.328 * * *$ \\
\hline Gender & $0.113 * * *$ & -0.007 & $0.106^{* * *}$ & $0.170 * * *$ & -0.006 & $0.165^{* * *}$ \\
\hline Education & 0.017 & $-0.042 * * *$ & -0.025 & $0.109 * * *$ & 0.014 & $0.123^{* * *}$ \\
\hline Social 1 & 0.033 & -0.014 & 0.018 & $0.105 * * *$ & -0.009 & $0.096 * * *$ \\
\hline Social 2 & 0.028 & 0.016 & 0.044 & $0.057 * *$ & -0.001 & $0.056^{* *}$ \\
\hline Single & $-0.253 * * *$ & $0.143 * * *$ & -0.109 & $-0.163 * * *$ & $0.121 * * *$ & -0.042 \\
\hline Married & $0.150 * * *$ & $0.063 * * *$ & $0.213^{* * *}$ & $0.136 * * *$ & $-0.043 * * *$ & $0.093 * * *$ \\
\hline Microwave & 0.050 & $0.037 *$ & 0.088 & $0.205 * * *$ & $0.038 * * *$ & $0.243^{* * *}$ \\
\hline Freezer & $-0.099 * *$ & -0.008 & $-0.107 * * *$ & $0.041 *$ & -0.014 & 0.026 \\
\hline
\end{tabular}

Prob.: Effect on probability of participation, Cond.: Effect on conditional level of expenditure, Uncond.: Effect on unconditional level of expenditure

$* * *$ significant at $1 \%$ level, $* *$ significant at $5 \%$ level, $*$ significant at $10 \%$ level

Significance levels are based on significance levels of the underlying marginal effects.

$\Omega$ The marginal effect of income is calculated including income ${ }^{2}$.

Table $7 \quad$ Unconditional income elasticity estimates evaluated at 1987 sample means for IHS heteroscedastic double-hurdle model

\begin{tabular}{lll}
\hline & 1987 & $1994^{* *}$ \\
\hline Unconditional & $0.380^{* * * *}$ & $0.347^{* * *}$ \\
Income & & \\
Elasticity $\Omega$ & & \\
\hline
\end{tabular}

*** significant at $1 \%$ level, ** significant at $5 \%$ level, * significant at $10 \%$ level

Significance levels are based on significance of underlying marginal effects.

$\Omega$ The marginal effect of income is calculated including income2.

*Evaluated at 1987 mean adjusted to 1994 market prices using the Consumer Price Index (Central Statistics Office, 1988, 1995). 